\title{
A New Conceptual Design of the SNS Full Turn Fast Extraction Kicker Power Supply System*
}

\author{
W. Zhang, J. Sandberg, N. Tsoupas, J. Mi, R. Lambiase, C. Pai, \\ J. Tuozzolo, T. Nehring, and D. Warburton \\ Collider-Accelerator Department, Brookhaven National Laboratory, Upton, NY 11973
}

\begin{abstract}
The new conceptual design of full turn fast extraction kicker power supply system of the Spallation Neutron Source main ring will be presented in this paper. In this design, the extraction kicker power modulators will be located outside of the tunnel, as requested by the SNS Project. Its purpose is to minimize the components inside of the synchrotron tunnel. The high voltage modulator will use Blumlein pulser and hollow-anode thyratron structure, a parallel termination resistor and two transmission cables. Main advantages include: flexible system configuration for unipolar single drive or push-pull double drive of the kicker magnets, lower charging voltage, lower beam impedance, lower number of high voltage cables, and large design margin for implementation and future upgrade.
\end{abstract}

\section{INTRODUCTION}

The Spallation Neutron Source is an accelerator based neutron production facility for neutron science research. It is presently being build at Oak Ridge National Laboratory in Tennessee. This project is a collaboration of six DOE laboratories. Brookhaven National Laboratory is responsible for the main ring design and fabrication. The extraction fast kicker system is part of the design package.

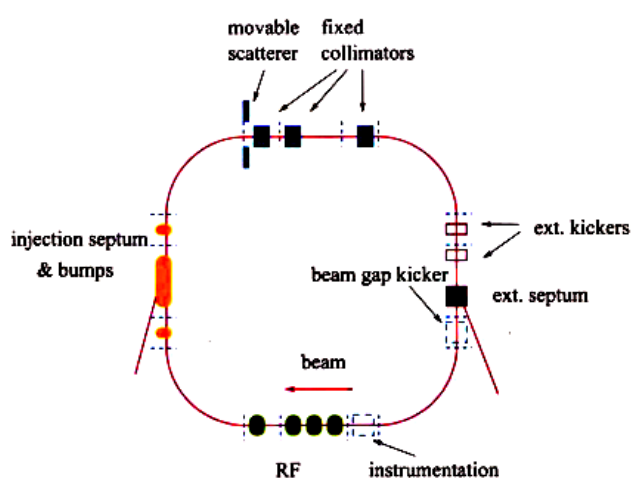

Figure 1. Omega Configuration of the Spallation Neutron Source Main Ring at ORNL
The basic layout of the SNS main ring is an omega configuration with FODO/doublet hybrid lattice. One of the four straight sections is used for extraction systems. The extraction fast kicker system consists of fourteen magnet sections and fourteen high voltage modulators. In the original design, it was proposed to have all modulators located inside the ring tunnel and directly attached to the magnets. This proposal has the advantage of low cost, low technical risk, and fast production. It would require a widened tunnel space, from 12 feet to 14 feet, to accommodate the high voltage modulators. The maintenance of the modulators would require people to work around hot magnet, which might be highly radioactive.

The injection and extraction region in the high intensity proton accelerator and accumulator ring tends to be heavy beam loss area, and radiation level might be very high. Also, in tunnel maintenance and repair will cause prolonged accelerator downtime, interrupt scientific experiments and increase operation cost considerably. Hence, it has been more and more a consensus in the accelerator community to minimize the equipment inside the beam tunnel. Upon the concerns of the potential radiation safety issues, operability and maintainability problems and other reasons, SNS project office directed a design change request to relocate all high voltage modulators to the new service building outside the ring tunnel.

Another issue related to the original kicker modulator design is the high beam impedance. It had a PFN with matched series termination resistor and a thyratron switch. During beam injection, acceleration and accumulation, the thyratron remain at opening state. Therefore, the beam would see an open circuit. This raised concerns, and it was suggested by Accelerator System Review Committee (ASRC) to look into a low beam impedance design.

Other than the above-mentioned amendments, the main parameter specification and the basic design requirement remain unchanged. The basic function of the extraction fast kicker system is to displace the beam vertically about $167.01 \mathrm{~mm}$ at the entrance of the Septum magnet with a deflection angle of 13.95 milliradian. The parameter specification is listed in Table 1.

\footnotetext{
${ }^{*}$ Work performed under the auspices of the U.S. Dept. of Energy.
} 
Table 1. Main Parameters of the SNS Extraction Fast Kicker System

\begin{tabular}{|c|c|}
\hline Beam Rigidity & $5.6575 \mathrm{~T}-\mathrm{M}$ \\
\hline Proton Momentum & $1.0 \mathrm{GeV}$ \\
\hline Extraction Type & Single-turn \\
\hline Magnet Window & Full aperture \\
\hline $\begin{array}{l}\text { Beam gap during } \\
\text { extraction }\end{array}$ & $250 \mathrm{nS}$ \\
\hline Maximum extraction rate & $60 \mathrm{~Hz}$ \\
\hline Pulse Flat-top length & $645 \mathrm{nS}$ \\
\hline Pulse Flat-top tolerance & $+/-3 \%$ \\
\hline Pulse rise time & $200 \mathrm{nS}(3 \%-97 \%)$ \\
\hline Pulse fall time & $<16.6 \mathrm{mS}$ \\
\hline Kicker strength & $\begin{array}{l}1.18 \text { to } 1.5 \text { mrad per } \\
\text { section }\end{array}$ \\
\hline $\begin{array}{ll}\text { Kicker } & \text { Horizontal } \\
\text { Aperture } & \\
\end{array}$ & $111.6 \mathrm{~mm}$ to $185.1 \mathrm{~mm}$ \\
\hline Kicker Vertical Aperture & $126.1 \mathrm{~mm}$ to $248.3 \mathrm{~mm}$ \\
\hline Kicker Effective Length & $480 \mathrm{~mm}$ per section \\
\hline $\begin{array}{ll}\text { Minimal } & \text { Charging } \\
\text { Voltage } & \end{array}$ & $\begin{array}{l}18.3 \mathrm{kV} \text { to } 26.6 \mathrm{kV} \text { per } \\
\text { module }\end{array}$ \\
\hline Minimal Pulse Current & $\begin{array}{l}1465 \text { A to } 2127 \text { A per } \\
\text { module }\end{array}$ \\
\hline
\end{tabular}

There are two groups of kicker magnet sections, one upstream and one downstream of the quadrupole doublet. The total magnetic length of kicker is $6.72 \mathrm{~m}$, equally distributed into two groups. The ferrite magnet with window frame structure is adapted. Each group of magnet sections will be housed inside a long vacuum chamber, and water-cooling will be used to aid the heat dissipation.

A critical requirement of the SNS extraction fast kicker system is the pulse surety. It demands the kicker system to be able to extract full beam within the acceptance of the RTBT line and transport to the target even with one of the fourteen modules, modulator and/or magnet section, failed to function. The constraint is that the change of the beam displacement and angle at the entrance of the Septum when a single kicker module fails is less than $27.5 \mathrm{~mm}$ and $2.03 \mathrm{mrad}$ respectively. On the system level, it can be managed easily with fourteen subsystems. Depending on the exact location, in most cases, the system can tolerate with two failed subsystems. This gives a higher availability of the overall system. Besides high-level system redundancy, one has to avoid the single-pointfailure mode through out the overall system integration as well.

\section{MERITS OF THE NEW DESIGN}

The extraction fast kicker system design change was directed in the middle of last year, while the SNS project has entered its detailed technical design phase.
At that time, the original kicker power supply modulator prototype had been build and tested, await for approval of quantity production. To come up with a new design to meet the SNS requirement and to minimize the impact on cost, schedule, manpower and environment, we evaluated different options.

Logically, the first option was to move modulators out and feed the pulse to the magnet with long coaxial cables. The engineering analysis based on the original scheme suggested a more than $60 \mathrm{kV}$ operating voltage to meet strength requirement, which is much higher than the $35 \mathrm{kV}$ limitation of original designed modulators. In addition, a total of more than ninety high voltage coaxial cables for the system, additional cable tray and tunnel penetrations also raised environmental and installation concerns. An in-tunnel termination and compensation box attached to each section of magnet would remain to be an operation and maintenance problem, etc.

Therefore, a new conceptual design was proposed. This design utilizes

1. The Blumlein Pulse Forming circuit to lower the voltage during energy storage;

2. The parallel resistor to lower beam impedance;

3. The full current reflection at magnet end to double the output;

4. The Hollow-Anode thyratron to handle reverse current;

5. The diode-resistor brunch to minimize reflection;

6. Two coaxial cables per each modulator for output pulse transmission.

The basic layout of the SNS Extraction Fast Kicker System is shown in Figure 2.

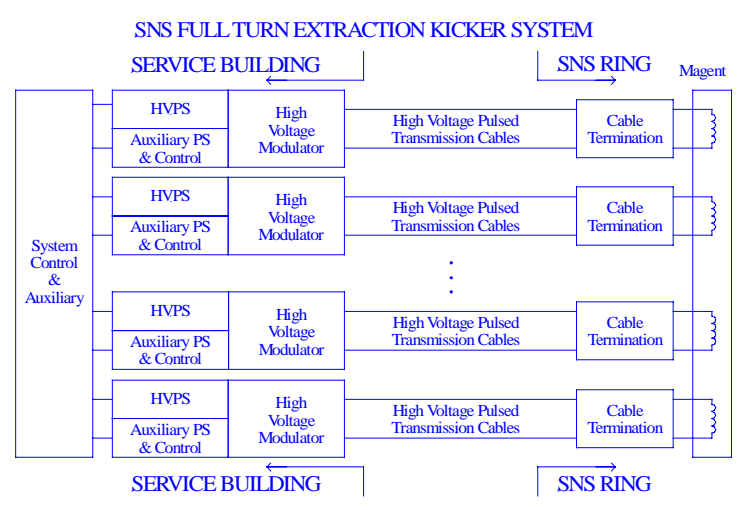

Figure 2. The SNS Extraction Fast Kicker System Layout.

This system can be arranged in single-drive per magnet section, as shown in Figure 3, or the push-pull fashion to serve a double-drive split magnet structure as shown in Figure 4. In the push-pull arrangement, one thyratron has to be floating at pulsed high voltage.

To implement this design, it would be the best to use transmission lines to construct Blumlein line pulser, 
and coaxial structure for switch tank and connection joints. In principle, it can be done with double-deck lumped element PFN, if the parasitic inductance can be tightly controlled.

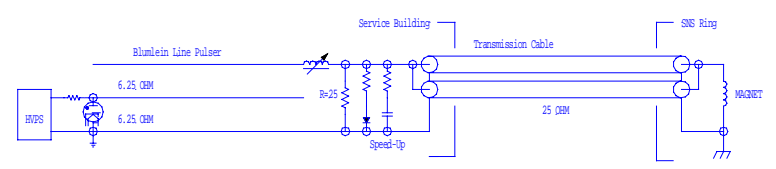

Figure 3. The SNS Extraction Fast Kicker Main Circuit Diagram.

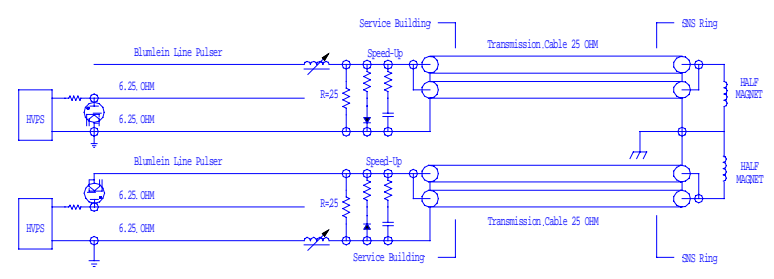

Figure 4. The Push-Pull Option Main Circuit Diagram.

All critical components necessary to implement this design are commercially available. Furthermore, the components will be operating well within their manufacture specifications to meet the SNS project requirements.

The main advantage of this new design is that

1. It will have a lower operation voltage;

2. It has a higher design margin, $90 \%$ to $173 \%$ above specification per subsystem;

3. It provides flexibility of the magnet layout, uni-polar or push-pull;

4. It avoids expensive tunnel expansion;

5. There will be no active and dissipative components required in the ring tunnel;

6. It requires much lesser number of high cost transmission cables per subsystem;

7. There will be no additional tunnel penetrations required;

8. There will be no additional cable tray load;

9. The maintenance in radiation area can be minimized;

10. It offers better operability and maintainability;

11. It maintained required system redundancy;

12. It offers lower beam impedance.

With modulators located in the service building, the insulating fluid will be used to minimize interconnection space and to increase high voltage stability.

\section{MODEL TEST}

The preferred implementation of the Blumlein structure is the transmission lines. However, the discrete component double-deck PFN is considered to be easier for mechanical packaging. A ten percent scale proof-of-principle circuit model has been build. It consists of $10 \mathrm{~L}-\mathrm{C}$ sections per PFN, two 50-ohm RF transmission cables, a 25-ohm parallel resistor, a small thyratron and an air core inductor. The test results suggest the simplified PFN approach is doable, but the stray inductance of the switching, inter-connection, capacitors shall be well controlled to satisfy the waveform specifications.

The Figure $5 \mathrm{a}$ and Figure $5 \mathrm{~b}$ are the test results of the actual circuit model. The load current is 290 amperes, about 14.5 percent of the required average magnet current level.

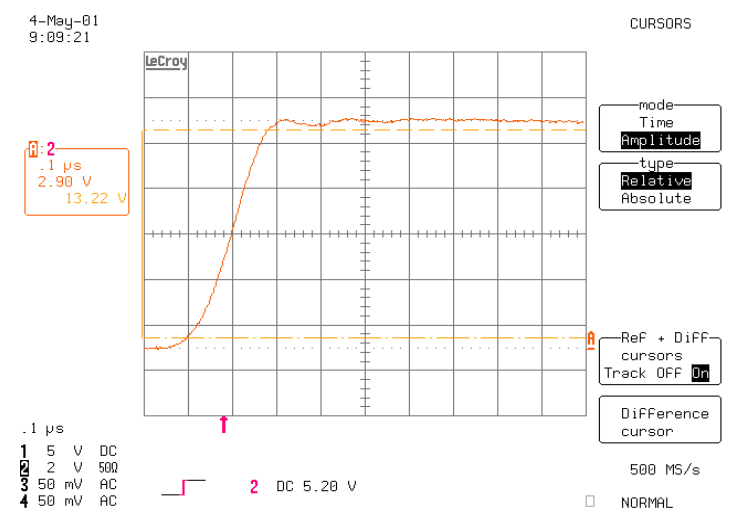

Figure 5a. The output current waveform of the circuit model with 100 nano-second per division horizontal scale.

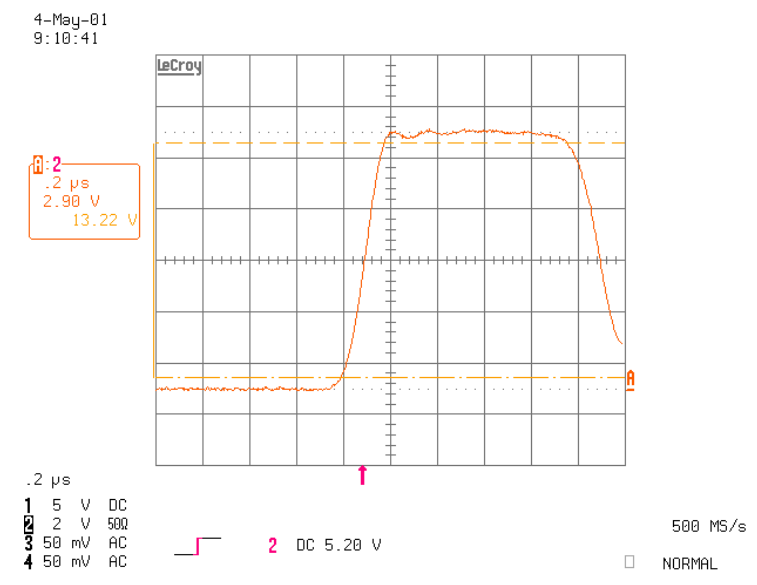

Figure $5 \mathrm{~b}$. The output current waveform of the circuit model with 200 nano-second per division horizontal scale.

The model test results are satisfactory. We are in the process to build a full-scale prototype modulator. It will consist of $15 \mathrm{~L}-\mathrm{C}$ sections per PFN to improve the performance.

\section{ACKNOWLEDGEMENT}

We would like to express our appreciation to W.A. Morris, D. Wootton and J.W. Gray of ISIS, R. Cassel of SLAC, R. Cutler, K. Rust, D. Anderson and P. Holik of SNS for their valuable contribution and suggestion. 